\title{
Erratum to: Hepatorenal Syndrome: Are We Missing Some Prognostic Factors?
}

\author{
Marco Olivera-Martinez $\cdot$ Harlan Sayles • \\ Renuga Vivekanandan · Sharlene D' Souza • \\ Marius C. Florescu
}

Published online: 1 September 2011

(C) Springer Science+Business Media, LLC 2011

\section{Erratum to: Dig Dis Sci}

DOI 10.1007/s10620-011-1861-1

In the published article first author's surname appears as "Martinez" which is incorrect because Olivera is a hyphenated part of his last name. The correct surname is Olivera-Martinez.

The online version of the original article can be found under doi:10.1007/s10620-011-1861-1.

M. Olivera-Martinez $\cdot$ S. D' Souza

Section of Gastroenterology and Hepatology,

University of Nebraska Medical Center,

983040 Nebraska Medical Center,

Omaha, NE 69198-3040, USA

e-mail: molivera@unmc.edu

S. D' Souza

e-mail: sdsouza@unmc.edu

H. Sayles

Department of Biostatistics, University of Nebraska Medical

Center, 983040 Nebraska Medical Center,

Omaha, NE 69198-3040, USA

e-mail: hsayles@unmc.edu

R. Vivekanandan

Section of Internal Medicine, University of Nebraska Medical

Center, 983040 Nebraska Medical Center,

Omaha, NE 69198-3040, USA

e-mail: rvivekanandan@unmc.edu

M. C. Florescu ( $\square)$

Section of Nephrology, University of Nebraska Medical Center, 983040 Nebraska Medical Center,

Omaha, NE 69198-3040, USA

e-mail: mflorescu@unmc.edu 